\title{
Challenges with Multi-Dimensional Inventory Classifications and Optimization
}

\author{
Dinesh Dhoka ${ }^{1} \&$ Lokeswara Y. Choudary ${ }^{2}$ \\ ${ }^{1}$ SRM University, Kattankulathur, Chennai, India \\ ${ }^{2}$ Govt. Arts College for Men, Nandanam, Chennai, India \\ Correspondence: Dinesh Dhoka, New \# 9 Poes Road 2nd Street Teynampet Chennai, Pin 600018, India. Tel: \\ 91-94-4465-3852. E-mail: dinesh.dhoka@gmail.com
}

\author{
Received: November 1, 2014 Accepted: December 4, 2014 Online Published: January 14, 2015 \\ doi:10.5539/ass.v11n4p365 \\ URL: http://dx.doi.org/10.5539/ass.v11n4p365
}

\begin{abstract}
The level of automation in Inventory Management is increasing day by day. In ERPs various parameters have to be defined to achieve even simple levels of automation like Reorder-Point, Minimum Order Quantity, Lot-Size, Lead-Time etc. Inventory Management with today's ERP systems can become simpler if the parameter settings of Materials Requirement Planning (MRP) and Master Production Schedule (MPS) are clearly understood and mapped. Various Inventory Classification methods are used like the ABC, XYZ, VED, FSN, HML, SDE etc. to group the products and maintain similar parameter settings for different group of products. Each parameter setting and product classifications have underlying assumptions. In our daily business the underlying assumptions may often be overlooked. The primary objective in this study is to highlight one of the assumptions taken for granted and to find an optimized solution for Inventory Classification for this assumption. This in turn can help enterprises be more flexible with better managed inventory.
\end{abstract}

Keywords: ABC-XYZ classification analysis, inventory management optimization

\section{Introduction}

Sustainability for today's Enterprise largely depends upon the variety of products they can offer to their customers. Therefore most companies today are increasing the range of products in the portfolio. Due to customer demands and competition, companies are forced to introduce new products and at the same time often reluctant to take decisions to discontinue obsolete items. This results in ever increasing range of product portfolio. As the size of the product portfolio increases, the challenges in terms of planning, procurement, storage, distribution and sales also increase. At the same time, companies have to ensure that their Supply Chains are more agile, robust and flexible. When materials pass through the entire Supply Chain, the automated parameter settings can have cascading effects. Complex algorithms, measures and checks are built in different functions of the Supply Chain. Because of these complexities companies are now forced to ensure inventories are quantitatively and qualitatively (Torabi, Hatefi, Saleck, \& Pay 2012) classified and managed. On one side customers are expecting more and more varieties of products and on the other side there is pressure on maintaining optimum levels of inventory for Finished Goods, Semi-Finished Goods and Raw Materials.

\subsection{Challenges in Efficient Planning}

Manufacturing companies have to ensure a wide range of resources are brought together to efficiently create items that satisfy customer needs. If all the resources are not synchronized, companies may not make profits. If companies have to be successful, production and manufacturing processes have to be planned carefully which in simple terms is called 'PP'. Through 'PP' the entire production process can be tracked, right from product conceptualization, design, manufacturing, storage and distribution. Planning also includes evaluation of existing production, possibilities of improvements in existing systems and requirements of products that may be planned for future releases.

Like most business strategies, 'PP' is designed to generate higher profits. Most production planning methods, like lean manufacturing, are used to reduce error and increase efficiency. PP is done to efficiently use all the resource of the company like machines, infrastructure, man-hours etc. Seamless integration of these resources is an important virtue of a good 'PP' system. Also finding ways for all of them to work together as seamlessly as 
possible. Other virtues include flexibility, scalability and agility. Production planning strategies include managing and maintaining different metrics for operational control.

\subsection{Unexpected Costs}

Budgeting is done to keep the overall production costs under control. All production strategies revolve around these budgets. Therefore budgets have to include costs of labor, raw materials, working capital, machinery, depreciation, transportation, inventory-holding-costs, insurance etc. Cost estimating is essential to determine a production strategy that will be within budget. Some of these costs may be fixed like raw material, Infrastructure, etc. But the real challenge is to keep the variable costs under control. When projects and production gets delayed, these variable costs can become very significant. Also when raw material and finished goods inventories are not managed efficiently the variable costs can have significant effect on profits.

\subsection{Scheduling}

For estimating cost, duration of the production needs to be known. To optimize expenses, all resources have to be scheduled appropriately. Different work centers have capacity constraints which plays an important role in production planning. The requirements of different phases of production have to be considered.

\subsection{Management of Surprises}

Though budgeting addresses the challenges associated with variable cost, there may be some un-foreseen elements that can impact production and production costs. Murphy's Law defines these effects. Adding 20 percent to your best estimate is a good rule of thumb. Production tasks going exactly as planned are rare. To handle surprises, Managers today use Safety Stock parameters to ensure production lines are not interrupted. These Safety Stock parameters are so often miss-used and managers may not realize its impact on the inventory until major damage is already done.

\section{Inventory Management}

Demands on the Supply Chain are increasing day by day. Due to innovation in technology, product life cycles are reducing. As the processes and product ranges become complex, management of Inventory also becomes complex. Based on the maturity levels of the processes, companies have to keep improving and innovating Inventory Management techniques. Various methodologies and techniques can be implemented to optimize the use of resources. To simplify Inventory Management, managers apply the concept of Importance and Exception. Based on these concepts, inventory is classified into different groups based on value, quantity, demand, availability and sometimes even weight and volume. Some of the classification methods (Mohammaditabara, Ghodsypoura, \& O'Brienb, 2012) are known as ABC, XYZ, VED, FSN, HML, SDE etc.

\subsection{Assumptions in Inventory Classifications}

Most Inventory classification methods apply 3 levels and more or less follow the Pareto Principle. As per this principle $80 \%$ of the Revenue is contributed by $20 \%$ of the Items. The focus shifts totally on the $20 \%$ of the items. The remaining $80 \%$ of the items are categorized based on convenience. Let's say this $80 \%$ is further split into 2 more levels as given below.

Table 1. Percentage and distribution on ABC classification

\begin{tabular}{lll}
\hline Category & Percentage & Distribution \\
\hline A & $80 \%$ & $20 \%$ \\
B & $80-95 \%$ & $30 \%$ \\
C & $95-100 \%$ & $50 \%$ \\
\hline
\end{tabular}

The approximate distribution is also mentioned in the table above. These percentages and distribution is often taken for granted. Typically in an automated process and ERP systems various parameters for planning and inventory management is based on these categorizations (Millstein, Yang, \& $\mathrm{Li}, 2013$ ). Typically the ' $\mathrm{C}$ ' class items would not have any parameters defined for planning because of their financial impact. Therefore there is a need to classify items based on the consistency and predictability of the movement. Items can further be classified as XYZ. Most highly predictable items are classified as ' $\mathrm{X}$ ', items with variations in movement are classified as ' $\mathrm{Y}$ ' and items which are highly unpredictable are classified as ' $\mathrm{Z}$ '. This consistency and predictability of the items is derived from Standard Deviation and Coefficient of Variation. These two categorizations can be merged in a 2-Dimensional format and we get this matrix given below. 
Table 2. ABC-XYZ 2 dimensional matrix

\begin{tabular}{lllll}
\hline \multirow{2}{*}{ 2D } & & \multicolumn{3}{l}{ Consistency of the stock movement } \\
& & X (High) & Y(Med) & Z(Low) \\
\hline \multirow{3}{*}{ Value of stock movement for the period } & A (High) & AX & AY & AZ \\
& B(Med) & BX & BY & BZ \\
& C(Low) & CX & CY & CZ \\
\hline
\end{tabular}

Typically to minimize inventories the following strategies are used.

1) Just-In-Time sourcing (Wagner \& Silveira-Camargos, 2011) is done for AX, AY, CX and BX items on Time Based (Order Cycle Method).

2) 'BY' is done of individual sourcing based on Stock Levels.

3) Demand based sourcing is done for $\mathrm{AZ}, \mathrm{BZ}, \mathrm{CY}$ and $\mathrm{CZ}$ items with safety stocks.

Nearly $40 \%$ of the items would be defined with Safety Stocks. This can result in increase of inventory levels if it is not efficiently managed. The ' $\mathrm{C}$ ' items will also include the non-moving items. Consider this example from a Plastics-Auto-Component manufacturing company with 330 items in their inventory. When the ABC and XYZ analysis in done for the period December 2012 to November 2013, the typical distribution would be as follows.

Table 3. STD ABC-XYZ distribution

\begin{tabular}{lll}
\hline $\begin{array}{l}\text { Dec12-Nov13 } \\
\text { ABC/XYZ }\end{array}$ & No. of Items & Distribution \\
\hline A & 66 & $20 \%$ of 330 \\
B & 99 & $30 \%$ of 330 \\
C & 165 & $50 \%$ of 330 \\
X & 66 & $20 \%$ of 330 \\
Y & 99 & $30 \%$ of 330 \\
Z & 165 & $50 \%$ of 330 \\
\hline
\end{tabular}

In reality there are only 175 active items in the total number of 330 items in the item master. Most of the items would get identified as 'A' and ' $B$ ' or ' $\mathrm{X}$ ' and ' $\mathrm{Y}$ '. The remaining 155 items (330-175) would be classified as 'C' and ' $\mathrm{Z}$ '. For these items if safety stocks are defined, it may lead to unnecessary inventory. Most literature and Inventory Policies define three levels of product classification. There is a need to add another level in these classifications which denotes as inactive or non-moving product. A typical 4X4 matrix is given below.

Table 4. ABC-XYZ 4X4 matrix

\begin{tabular}{lllll}
\hline & $\mathbf{A}$ & $\mathbf{B}$ & $\mathbf{C}$ & Inactive \\
\hline $\mathbf{X}$ & $\mathrm{AX}$ & $\mathrm{AY}$ & $\mathrm{AZ}$ & -- \\
$\mathbf{Y}$ & $\mathrm{BX}$ & $\mathrm{BY}$ & $\mathrm{BZ}$ & -- \\
$\mathbf{Z}$ & $\mathrm{CX}$ & $\mathrm{CY}$ & $\mathrm{CB}$ & -- \\
Inactive & -- & -- & -- & Inactive-Inactive \\
\hline
\end{tabular}

\subsection{Challenging the 'Assumption': Period for Data Analysis}

The period of analysis plays a vital role in inventory classification. If $\mathrm{ABC}$ and XYZ classifications are taken separately, the variations in each of the classification can be very significant. If you consider smaller periods of data, the number of active items would be less in comparison to larger periods of data. In a typical case study the variation of ' $A$ ' class items for different periods of data is given below. 
Table 5. ABC classification

\begin{tabular}{llllllllllll}
\hline S No & $\begin{array}{l}\text { Period } \\
\text { (Months) }\end{array}$ & Feb 12 & Mar 12 & Apr 12 & May 12 & Jun 12 & $\sim$ & Apr 13 & May 13 & Jun 13 & Jul 13 \\
\hline 1 & $\mathbf{1 M}$ & 10 & 9 & 9 & 12 & 15 & $\sim$ & 13 & 8 & 7 & 10 \\
2 & $\mathbf{2 M}$ & 12 & 11 & 11 & 13 & 17 & $\sim$ & 13 & 12 & 8 & 9 \\
3 & $\mathbf{3 M}$ & 15 & 12 & 12 & 14 & 17 & $\sim$ & 15 & 13 & 10 & 9 \\
4 & $\mathbf{4 M}$ & 16 & 15 & 14 & 15 & 16 & $\sim$ & 16 & 15 & 12 & 11 \\
5 & $\mathbf{5 M}$ & 16 & 16 & 17 & 16 & 17 & $\sim$ & 17 & 16 & 14 & 13 \\
6 & $\mathbf{6 M}$ & 17 & 17 & 18 & 18 & 18 & $\sim$ & 17 & 16 & 15 & 15 \\
7 & $\mathbf{7 M}$ & 18 & 18 & 18 & 19 & 20 & $\sim 17$ & 16 & 15 & 15 \\
8 & $\mathbf{8 M}$ & 17 & 18 & 19 & 20 & 21 & $\sim 18$ & 16 & 15 & 15 \\
9 & $\mathbf{9 M}$ & 18 & 17 & 19 & 20 & 21 & $\sim$ & 19 & 17 & 15 & 15 \\
10 & $\mathbf{1 2 M}$ & 20 & 19 & 20 & 21 & 22 & $\sim 21$ & 20 & 18 & 17 \\
\hline
\end{tabular}

When we compare the 1-Month data in first line and 12-Month data in the last line the number for 'A' class item vary drastically. The difference is nearly two times. For planning and extrapolation identifying the most optimized period for data analysis becomes a big challenge because similar challenges are there for XYZ classification also as shown below.

Table 6. XYZ classification

\begin{tabular}{llllllllllll}
\hline S No & $\begin{array}{l}\text { Period } \\
\text { (Months) }\end{array}$ & Feb 12 & Mar 12 & Apr 12 & May 12 & Jun 12 & $\sim$ & Apr 13 & May 13 & Jun 13 & Jul 13 \\
\hline 1 & $\mathbf{1 M}$ & 11 & 11 & 10 & 13 & 11 & $\sim$ & 13 & 16 & 14 & 12 \\
2 & $\mathbf{2 M}$ & 14 & 15 & 15 & 16 & 17 & $\sim$ & 21 & 21 & 22 & 19 \\
3 & $\mathbf{3 M}$ & 19 & 17 & 19 & 19 & 19 & $\sim$ & 24 & 26 & 25 & 25 \\
4 & $\mathbf{4 M}$ & 21 & 21 & 20 & 22 & 21 & $\sim$ & 25 & 29 & 29 & 27 \\
5 & $\mathbf{5 M}$ & 23 & 23 & 23 & 23 & 24 & $\sim$ & 29 & 30 & 32 & 31 \\
6 & $\mathbf{6 M}$ & 25 & 26 & 25 & 27 & 25 & $\sim$ & 29 & 33 & 33 & 33 \\
7 & $\mathbf{7 M}$ & 27 & 28 & 27 & 28 & 29 & $\sim$ & 31 & 33 & 35 & 34 \\
8 & $\mathbf{8 M}$ & 29 & 29 & 29 & 30 & 30 & $\sim$ & 34 & 35 & 36 & 36 \\
9 & $\mathbf{9 M}$ & 30 & 31 & 30 & 33 & 32 & $\sim$ & 36 & 37 & 37 & 37 \\
10 & $\mathbf{1 2 M}$ & 34 & 34 & 35 & 36 & 36 & $\sim 41$ & 41 & 43 & 42 \\
\hline
\end{tabular}

When the XYZ classification is studied the difference between 1-Month and 12-Month data is more significant. If multi-dimensional approach is considered it becomes even more important that the optimized planning period is used for planning and extrapolation.

\section{Optimization thru Measure of Dispersion}

The suggested method for Optimization of 'Period' of Planning Data is through the measure of dispersion. For any specific period of planning, items jump from one classification to another. If this jump and be measured, quantified and compared then optimization can be achieved.

\subsection{Quantum of Dispersion}

Table 7. ABC-XYZ substitutions for quantification

\begin{tabular}{lll}
\hline $\mathrm{A}$ is replaced by & $1 \mathrm{X}$ is replaced by & 1 \\
$\mathrm{~B}$ is replaced by & $2 \mathrm{Y}$ is replaced by & 2 \\
$\mathrm{C}$ is replaced by & $3 \mathrm{Z}$ is replaced by & 3 \\
BLANK is replaced by & 4 BLANK is replaced by & 4 \\
\hline
\end{tabular}


Step 1. The classification of A, B, C, Blank and X, Y, Z, Blank are replaced by the alphabetic number 1, 2, 3, and 4.

Step 2. This numeric values of each period are compared (mathematically subtracted) with the previous period and this difference is Squared.

Step 3. For each type of classification the squared difference is added to compute the total variation

Quantified ABC and XYZ deviation is given below in separate tables.

Table 8. Quantification of ABC deviation

\begin{tabular}{lllllllll}
\hline & Dec-12 & Jan-13 & Feb-13 & Mar-13 & Apr-13 & May-13 & Jun-13 & Jul-13 \\
\hline $\mathbf{1 M}$ & 107 & 98 & 98 & 119 & 135 & 107 & 111 & 116 \\
$\mathbf{2 M}$ & 70 & 37 & 90 & 63 & 60 & 89 & 47 & 56 \\
$\mathbf{3 M}$ & 61 & 42 & 41 & 80 & 40 & 69 & 61 & 30 \\
$\mathbf{4 M}$ & 45 & 44 & 52 & 44 & 59 & 50 & 39 & 43 \\
$\mathbf{5 M}$ & 25 & 34 & 47 & 49 & 27 & 44 & 26 & 28 \\
$\mathbf{6 M}$ & 27 & 14 & 45 & 54 & 31 & 29 & 34 & 18 \\
$\mathbf{7 M}$ & 29 & 22 & 31 & 53 & 29 & 35 & 19 & 22 \\
$\mathbf{8 M}$ & 14 & 26 & 27 & 33 & 37 & 31 & 23 & 10 \\
$\mathbf{9 M}$ & 37 & 14 & 30 & 37 & 21 & 39 & 31 & 16 \\
$\mathbf{1 2 M}$ & 37 & 12 & 30 & 33 & 14 & 27 & 26 & 18 \\
\hline
\end{tabular}

Table 9. Quantification of XYZ deviation

\begin{tabular}{lllllllll}
\hline & Dec-12 & Jan-13 & Feb-13 & Mar-13 & Apr-13 & May-13 & Jun-13 & Jul-13 \\
\hline $\mathbf{1 M}$ & 88 & 99 & 86 & 99 & 106 & 90 & 133 & 108 \\
$\mathbf{2 M}$ & 83 & 40 & 67 & 50 & 62 & 94 & 72 & 78 \\
$\mathbf{3 M}$ & 61 & 53 & 37 & 60 & 44 & 75 & 70 & 44 \\
$\mathbf{4 M}$ & 41 & 49 & 53 & 35 & 50 & 58 & 44 & 54 \\
$\mathbf{5 M}$ & 30 & 40 & 44 & 44 & 39 & 53 & 38 & 43 \\
$\mathbf{6 M}$ & 24 & 23 & 43 & 51 & 41 & 55 & 47 & 19 \\
$\mathbf{7 M}$ & 41 & 21 & 35 & 38 & 44 & 49 & 46 & 45 \\
$\mathbf{8 M}$ & 36 & 34 & 31 & 26 & 45 & 38 & 39 & 32 \\
$\mathbf{9 M}$ & 38 & 29 & 37 & 33 & 34 & 43 & 39 & 25 \\
$\mathbf{1 2 M}$ & 18 & 52 & 26 & 28 & 23 & 23 & 32 & 41 \\
\hline
\end{tabular}

\subsection{A Inference from Quantification}

Table 10. T-test statistics for ABC classification

\begin{tabular}{lllllllllll}
\hline & $\mathbf{1 M}$ & $\mathbf{2 M}$ & $\mathbf{3 M}$ & $\mathbf{4 M}$ & $\mathbf{5 M}$ & $\mathbf{6 M}$ & $\mathbf{7 M}$ & $\mathbf{8 M}$ & $\mathbf{9 M}$ & $\mathbf{1 2 M}$ \\
\hline $\mathbf{1 M}$ & & 0.007 & 0.000 & 0.000 & 0.000 & 0.000 & 0.000 & 0.000 & 0.000 & 0.000 \\
$\mathbf{2 M}$ & 0.007 & & 0.081 & 0.009 & 0.004 & 0.004 & 0.000 & 0.001 & 0.000 & 0.004 \\
$\mathbf{3 M}$ & 0.000 & 0.081 & & 0.244 & 0.025 & 0.011 & 0.012 & 0.004 & 0.001 & 0.007 \\
$\mathbf{4 M}$ & 0.000 & 0.009 & 0.244 & & 0.027 & 0.119 & 0.067 & 0.002 & 0.005 & 0.005 \\
$\mathbf{5 M}$ & 0.000 & 0.004 & 0.025 & 0.027 & & 0.556 & 0.541 & 0.070 & 0.029 & 0.124 \\
$\mathbf{6 M}$ & 0.000 & 0.004 & 0.011 & 0.119 & 0.422 & & 0.681 & 0.613 & 0.438 & 0.361 \\
$\mathbf{7 M}$ & 0.000 & 0.000 & 0.012 & 0.067 & 0.682 & 0.681 & & 0.161 & 0.123 & 0.180 \\
$\mathbf{8 M}$ & 0.000 & 0.001 & 0.004 & 0.002 & 0.106 & 0.613 & 0.161 & & 0.878 & 0.363 \\
$\mathbf{9 M}$ & 0.000 & 0.000 & 0.001 & 0.005 & 0.053 & 0.438 & 0.123 & 0.878 & 0.459 \\
$\mathbf{1 2 M}$ & 0.000 & 0.004 & 0.007 & 0.005 & 0.042 & 0.361 & 0.180 & 0.363 & 0.459 & \\
\hline
\end{tabular}


As the period of analysis increases from 1 Month to 12 Months the quantum of deviation reduces but we do not get a conclusive result for optimization. The statistical t-test data are compared for all periods from 1 Month to 12 Months. The table below gives the t-test data for both ABC and XYZ.

Table 11. T-test statistics for XYZ classification

\begin{tabular}{|c|c|c|c|c|c|c|c|c|c|c|}
\hline & $1 \mathrm{M}$ & $2 M$ & $3 \mathrm{M}$ & $4 M$ & $5 M$ & $6 M$ & $7 M$ & $8 \mathrm{M}$ & $9 M$ & $12 M$ \\
\hline $1 \mathrm{M}$ & & 0.001 & 0.000 & 0.000 & 0.000 & 0.000 & 0.000 & 0.000 & 0.000 & 0.000 \\
\hline $2 M$ & 0.001 & & 0.207 & 0.023 & 0.001 & 0.001 & 0.001 & 0.001 & 0.000 & 0.000 \\
\hline $3 \mathbf{M}$ & 0.000 & 0.207 & & 0.421 & 0.015 & 0.004 & 0.001 & 0.002 & 0.000 & 0.000 \\
\hline $4 M$ & 0.000 & 0.023 & 0.421 & & 0.018 & 0.015 & 0.004 & 0.000 & 0.003 & 0.001 \\
\hline $5 M$ & 0.000 & 0.001 & 0.015 & 0.018 & & 0.346 & 0.048 & 0.061 & 0.109 & 0.017 \\
\hline $6 M$ & 0.000 & 0.001 & 0.004 & 0.015 & 0.368 & & 0.640 & 0.171 & 0.383 & 0.102 \\
\hline $7 \mathrm{M}$ & 0.000 & 0.001 & 0.001 & 0.004 & 0.104 & 0.640 & & 0.212 & 0.590 & 0.169 \\
\hline $8 M$ & 0.000 & 0.001 & 0.002 & 0.000 & 0.024 & 0.171 & 0.212 & & 0.510 & 0.922 \\
\hline $9 M$ & 0.000 & 0.000 & 0.000 & 0.003 & 0.117 & 0.383 & 0.590 & 0.510 & & 0.065 \\
\hline $12 M$ & 0.000 & 0.000 & 0.000 & 0.001 & 0.034 & 0.102 & 0.169 & 0.922 & 0.065 & \\
\hline
\end{tabular}

Based on the t-test data in the above tables, it is evident that there is no significant difference between quanta of deviation observed for 6-Months to 12 Months shown as shaded grey above tables as the values are greater than 0.05 . Therefore we can conclude that at least six months data must be considered for extrapolation.

\section{Conclusion}

Proper application of the Pareto Principle has to be done when it is applied to product classification based on $\mathrm{ABC}$ and $\mathrm{XYZ}$. The inactive items have to be clearly identified and not clubbed with slow moving and random moving items. If a $4 \mathrm{X} 4$ matrix seems inappropriate even a $3 \mathrm{X} 3$ matrix with $\mathrm{A}, \mathrm{B} \&$ Inactive or $\mathrm{X}, \mathrm{Y}$ and Inactive may be considered. Most importantly before any data is extrapolated for long term planning, all the variables and assumptions need to be clearly understood and addressed. With the identification of Inactive items and optimized periods of data analysis, inventories can be more efficiently managed.

\section{References}

Millstein, M. A., Yang, L., \& Li, H. T. (2013, November). Optimizing ABC Inventory Grouping Decisions. International Journal of Production Economics.

Mohammaditabara, D., Ghodsypoura, S. H., \& O'Brienb, C. (2012, December). Inventory Control System Design by Integrating Inventory Classification and Policy Selection. International Journal of Production Economics, 140(2), 655-659. http://dx.doi.org/10.1016/j.ijpe.2011.03.012

Stößlein, M., Kanet, J. J., Gorman, M., \& Minner, S. (2013, April). Time-Phased Safety Stocks Planning and its Financial Impacts: Empirical Evidence based on European Econometric Data. International Journal of Production Economics.

Torabi, S. A., Hatefi, S. M., \& Pay, B. S. (2012). ABC Inventory Classification In The Presence Of Both Quantitative And Qualitative Criteria. Computers \& Industrial Engineering, 63, 530-537. http://dx.doi.org/ 10.1016/j.cie.2012.04.011

Wagner, S. M., \& Silveira-Camargos, V. (2011, October). Decision Model for the Application of Just-In-Sequence. International Journal of Production Research, 49(1), 5713-5736. http://dx.doi.org/10. $1080 / 00207543.2010 .505216$

\section{Copyrights}

Copyright for this article is retained by the author(s), with first publication rights granted to the journal.

This is an open-access article distributed under the terms and conditions of the Creative Commons Attribution license (http://creativecommons.org/licenses/by/3.0/). 